\title{
Enfermedad de Hansen. Una condición emergente en Chile
}

\author{
Álvaro San Martín ${ }^{1,3}$, Cristián Carrasco ${ }^{1,3}$, Alberto Fica ${ }^{1,3}$, \\ Maritza Navarrete', Juan Carlos Velásquez y Tania Herrera²
}

\footnotetext{
${ }^{1}$ Hospital Base de Valdivia. Valdivia, Chile. 2Programa Control y Eliminación Tuberculosis, MINSAL. Santiago,

${ }^{3}$ Universidad Austral de Chile. Valdivia, Chile.

Conflicto de Interés: ninguno. Financiamiento: ninguno.

Recibido: 30 de abril de 2018 Aceptado: 4 de diciembre de

Correspondencia a: Alberto Fica C. albertoficacubillos@gmail.com
}

\section{Hansen disease, an emergent condition in Chile}

Hansen's disease (HD) is caused by Mycobacterium leprae. It has a chronic course and preferentially affects the skin and the peripheral nerves. It's an emergent infection in Chile due to migration waves. This case report affecting a migrant worker from Haiti that presented several compatible skin lesions, with hypoesthesia and unilateral madarosis that appeared before arrival. The diagnosis of a multibacillary form was established by clinical findings, presence of fast acid bacilli on a direct skin smear, and inflammatory cell surrounding nerve endings and granulomas on skin biopsy. Besides, specific rpoB and $h s p 65$ gene segments from $M$. leprae were amplified from skin samples. Patient was treated with the WHO standard combined regimen for multibacillary forms during one year showing partial regression of skin lesions. Nasopharyngeal samples showed the presence of $M$. leprae rpoB copies detected by PCR decreasing until six months of therapy. Notifiable diseases databases showed a recent increment of cases, all related to migrant population. Hansen's disease is a new condition in Chile and clinicians should be aware of this possibility. Molecular tools may facilitate diagnosis and follow up.

Keywords: Multibacillary leprosy; Mycobacterium leprae; histology; polymerase chain reaction; drug therapy.

Palabras clave: Lepra multibacilar; Mycobacterium leprae; histología; reacción en cadena de la polimerasa, terapia.

\section{Introducción}

L a enfermedad de Hansen (EH) o lepra, es una infección bacteriana crónica producida por Mycobacterium leprae con compromiso cutáneo y neurológico periférico y que epidemiológicamente está en declinación en el mundo. En Chile, presenta un perfil emergente debido a las migraciones humanas, las que han aumentado en los últimos años con una aparición progresiva de casos importados (Figura 1). El número de nuevos casos de $\mathrm{EH}$ en el orbe ha disminuido de 265.661 a 210.758 entre los años 2006 y 2015, siendo evidente este descenso en todas las zonas geográficas, aunque más pronunciado en América ${ }^{1}$. Con excepción de Chile, en América, casi todos los países reportaban casos autóctonos o importados hacia el 2015. El número de casos nuevos anuales supera los 10.000 en Brasil, el segundo país con más casos en el mundo, seguido por Argentina, Venezuela, Colombia, Paraguay y Norteamérica con 100 a 999 casos nuevos por año y luego Perú, Uruguay, países centroamericanos, Guyana y Surinam con menos de 100 casos por año ${ }^{1}$. Esta cercanía con la EH ocurre en un escenario con un aumento progresivo de inmigrantes en Chile, con un incremento de los residentes extranjeros en el país desde un $0,7 \%$ el año 1982 (83.805) a 2,3\% el $2014(410.988)^{2}$. La mayor parte de estos inmigrantes provienen de Sudamérica (75\%) y se han asentado en grado variable, en todas las regiones de Chile. ${ }^{2}$ El influjo de migrantes específicos de cada país es muy dinámico con cifras crecientes o decrecientes en el tiempo, aunque entre los años 2014 y 2015, los grupos que más aumentaron correspondieron a ciudadanos de Haití $(+144 \%)$ y Venezuela $(+192 \%)$.

Estos antecedentes indican que los equipos de salud en Chile necesariamente experimentarán nuevos escenarios epidemiológicos con enfermedades transmisibles inhabituales en nuestra latitud, para los cuales no están necesariamente preparados y que no siempre están relacionados a viajes recientes, debido a sus largos períodos de incubación o prepatencia, recurrencias o cronicidad. En este perfil es posible considerar malaria, leishmaniasis, esquistosomiasis, estrongiloidasis, filariasis y enfermedad de Hansen. La falta de una experiencia clínica directa con estas enfermedades retrasa su reconocimiento y terapia oportuna, prolongando la morbilidad del paciente o incluso facilitando la transmisión en ciertos casos. Por ello, consideramos importante reportar estas enfermedades para facilitar la sospecha y detección de estas condiciones.

La experiencia clínica con la EH es prácticamente nula en nuestro país debido a la ausencia de casos autóctonos en Chile continental y al tratamiento de los últimos tres casos remanentes en el leprosario de Rapa Nui el año $1992^{3}$. Se conoce de un caso diagnosticado el año 1993 en un nativo de esta isla que migró a Chile continental ${ }^{4} \mathrm{y}$ de otro caso el 2007 en un ciudadano chileno que regresó de Paraguay luego de residir en esa zona por varios años ${ }^{5}$. Dado que la 
sospecha y diagnóstico de la EH descansa fundamentalmente en sus características clínicas y presencia de bacilos ácido alcohol resistentes (BAAR), la ausencia de casos en un país no endémico dificulta este acto inicial y podría hacer más relevante el concurso de técnicas histológicas y moleculares. Presentamos un caso de EH importado y analizamos sus aspectos microbiológicos, histológicos, moleculares y terapéuticos.

\section{Caso clínico}

Varón de 28 años, previamente sano, oriundo de Gonaives, Haití, sin casos familiares conocidos de enfermedad de Hansen y con vacunas al día. Ingresó a Chile el año 2016, residiendo inicialmente en Santiago, en una pieza individual con baño compartido con otras 15 personas. Se desplazó por razones laborales a Panguipulli, en la Región de los Ríos, donde residía con otra persona en la misma pieza. Fue derivado a Dermatología por un cuadro de dos años de evolución caracterizado por placas infiltradas asimétricas faciales, con algunas que comprometían el párpado izquierdo con madarosis e hipoestesia, sin hipopigmentación (Figura 2A, 3A). En las extremidades presentaba múltiples pápulo-placas hiperpigmentadas, con hipoestesia en algunas de ellas (Figura 2B). No se visualizó cicatriz de la vacuna BCG. La serología para VIH resultó negativa y las pruebas de laboratorio general fueron normales. La baciloscopia de una muestra de tejido lesional reveló múltiples bacilos ácido alcohol resistentes (BAAR) en empalizada (Figura 4). El estudio histológico de la lesión facial y de extremidades demostraron granulomas no necróticos que seguían los filetes nerviosos, alrededor de los vasos sanguíneos y glándulas sudoríparas, con tinción de Ziehl-Neelsen positiva, hallazgos compatibles con EH (Figura 5A, 5B). La baciloscopia no se cuantificó a través del índice bacilar, ya que se realizó en una muestra de biopsia, no de fluido linfático tisular en forma directa. Una segunda muestra de tejido se utilizó para la amplificación y secuenciación de los genes rpoB y hsp65 en el Instituto de Salud Pública de Chile, según los protocolos conocidos ${ }^{6,7}$. Los amplicones fueron purificados usando el kit de purificación de RPC QIAquick (Qiagen). Las secuencias de los genes fue determinada directamente usando el kit de amplificación BigDye 3.1 y un equipo de secuenciación ABIS PRISM 3.500 (Applied Biosystems). Las secuencias obtenidas fueron comparadas con aquellas disponibles en Genbank, EMBL (http://www.ebi.ac.uk), demostrando una identidad de $99 \%$ con la cepa de referencia de M. leprae Br4923 (número acceso FM211192.1).

El cultivo para micobacterias en medio líquido resultó negativo. Se clasificó como una EH multibacilar, tanto por criterio OMS (mayor a cinco lesiones) y por baciloscopia positiva y borderline lepromatosa (criterios

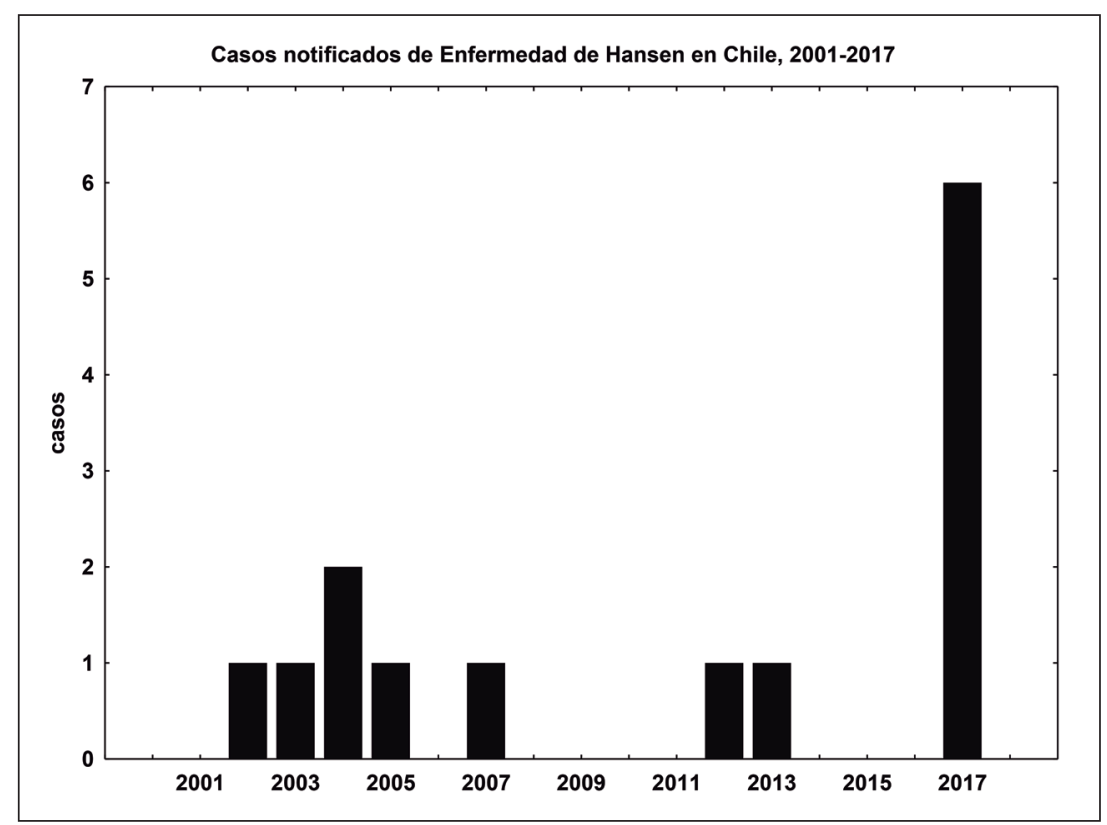

Figura 1. Casos reportados de enfermedad de Hansen desde el 2001 hasta el 2017 (parcial). Los datos fueron obtenidos a través de una solicitud al Ministerio de Salud por ley de transparencia 20.285.

Ridley \& Jopling), iniciándose tratamiento triasociado con rifampicina, clofazimina y dapsona. Transcurrieron tres meses entre el momento de la primera consulta y el inicio del tratamiento y cerca de dos años desde el comienzo de los síntomas. Se solicitó un estudio de actividad de glucosa-6-fosfato deshidrogenasa (G6PD) por la prueba

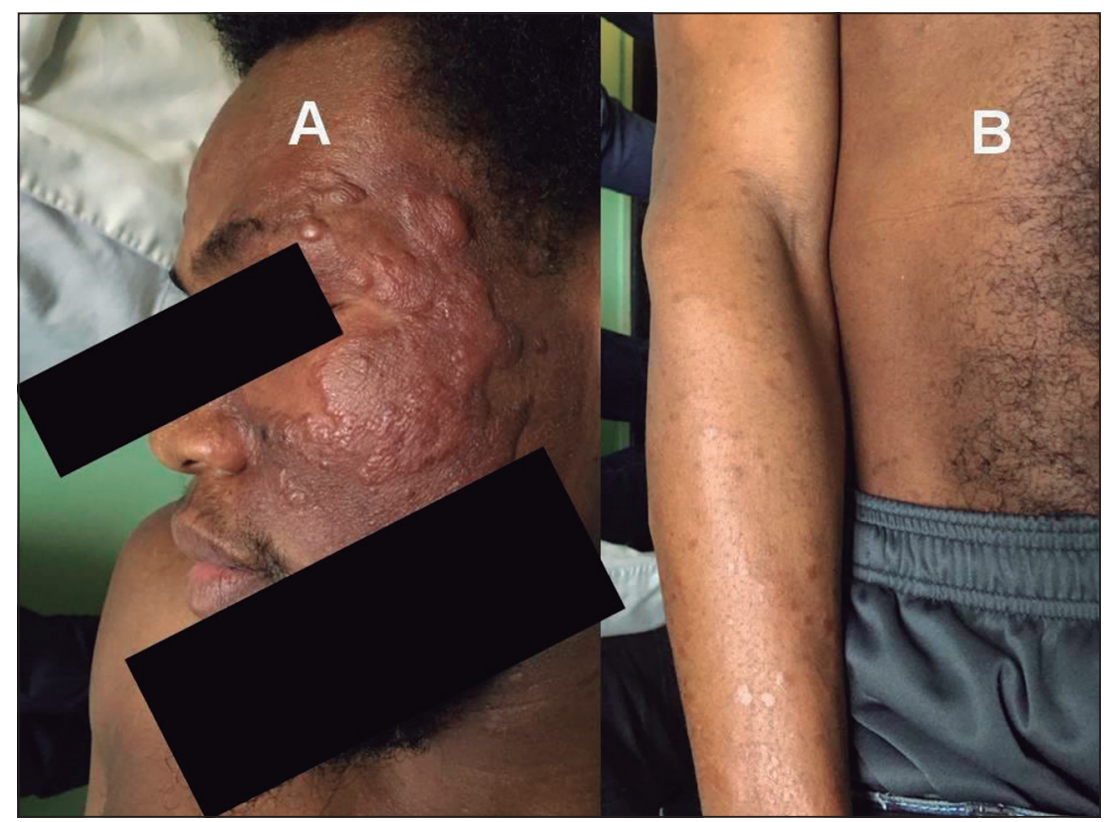

Figura 2. A: Extensa infiltración facial que compromete región malar y maxilar con pápulas hacia la región supraciliar. B. Placas pigmentadas en antebrazo. 


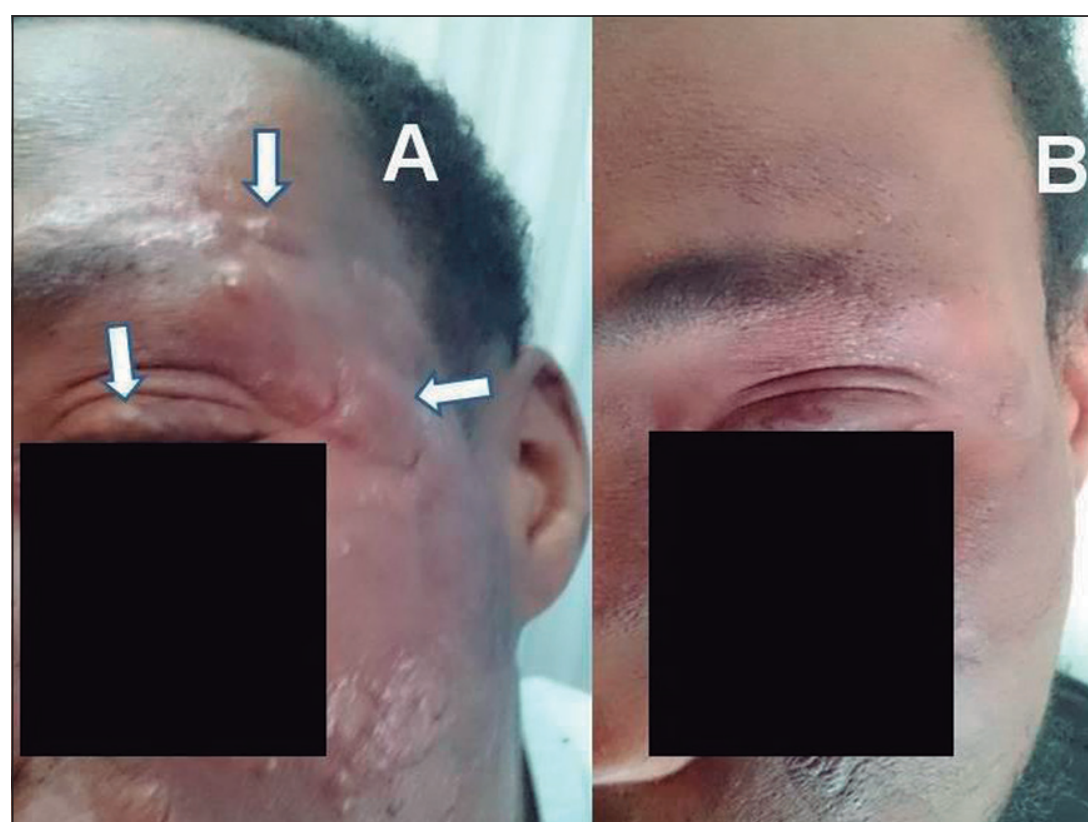

Figura 3. A: Imagen pre-tratamiento que demuestra pápulas sobre ceja izquierda y región malar con madarosis y nódulos en el párpado superior (flechas). B: Control a los dos meses que revela recuperación parcial de la madarosis, desaparición de placas supraciliares y en región malar.

Figura 5. A: Tinción hematoxilina-eosina $10 \mathrm{X}$ en muestra de piel que muestra extenso infiltrado inflamatorio que sigue un filete nervioso (flechas). B. Granuloma en biopsia de piel (flechas).

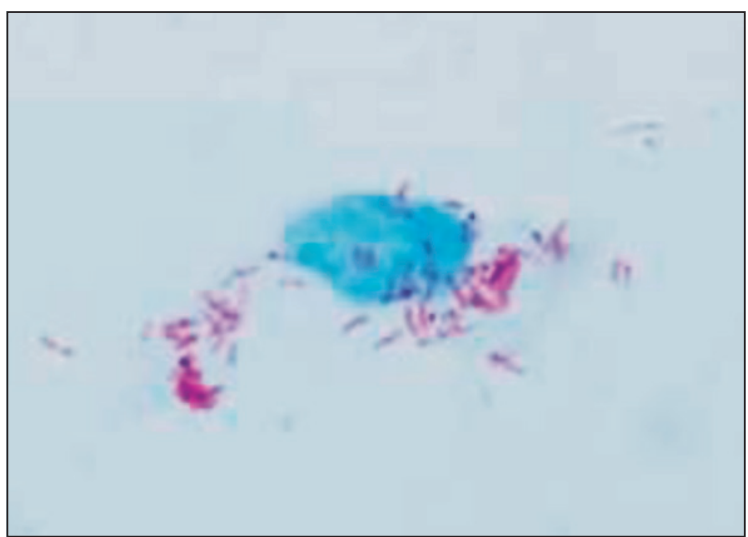

Figura 4. Tinción de Ziehl-Neelsen en muestra de tejido antes de iniciar tratamiento. Se observan numerosos BAAR, algunos en empalizada.

de Tonz-Betke que resultó normal. La evaluación oftalmológica descartó compromiso corneal. Durante el año de seguimiento el paciente no refirió efectos adversos, aunque los exámenes de laboratorio demostraron una anemia leve con una concentración de hemoglobina que descendió de 13,9 a $12 \mathrm{~g} / \mathrm{dl}$ y una neutropenia (1.400 cél/ $\mathrm{mm}^{3}$ ), fenómenos asociados al uso de dapsona. No se observaron secuelas con discapacidad. El seguimiento clínico reveló inicialmente una disminución de las lesiones (Figura 3B) y del ardor, sin impacto en las alteraciones sensitivas y con mantención de las placas en la cara. El estudio del único contacto conocido en la zona no reveló un caso concurrente.

Durante la terapia se tomaron, en diferentes momentos, muestras nasofaríngeas para conocer la duración de la portación nasofaríngea del agente. Se realizó un hisopado nasofaríngeo con tórula de nylon (flocked swab), las que fueron colocadas en medio de transporte universal $\left(\mathrm{UMT}-\mathrm{Copan}^{\mathrm{R}}\right.$ ) y analizadas por RPC en tiempo real. Se procedió a la centrifugación y obtención del pellet del cual se extrajo y purificó el ADN con el kit comercial Zymo, según instrucciones del fabricante. También se procedió a la extracción de $\mathrm{ADN}$ de las biopsias de piel incluidas en parafina, usando aproximadamente $20 \mathrm{mg}$ de material con el kit Quick DNA FFPE Kit (Zymo), de acuerdo con las especificaciones del fabricante, incluyendo un paso de pre-digestión con Proteinasa $\mathrm{K}$ de $4 \mathrm{~h}$ a $56^{\circ} \mathrm{C}$.

Para la detección del ADN de M. leprae de las muestras nasofaríngeas y de tejido, se realizo RPC en tiempo real con una curva de cuantificación de 2-2 x $10^{5}$ copias/ $\mathrm{mm}^{3}$, utilizando el kit Genesig (Primerdesign) contra el blanco rpoB, realizando la amplificación en un equipo Stratagene $3000 \mathrm{XP}$, según el protocolo del proveedor. Los resultados se presentan en la Figura 6 apreciándose la ausencia de detección de $M$. leprae desde el octavo mes de tratamiento. 


\section{Discusión}

La EH es una enfermedad crónica que compromete la piel y los nervios periféricos en diferentes formas. Las manifestaciones clínicas dependen más bien de la respuesta inmune celular que de la capacidad invasora de M. leprae, determinando un espectro de cuadros clínicos. Así, en un extremo se encuentra la forma tuberculoidea, caracterizada por la infiltración tisular de linfocitos CD4, con síntesis de IFN- $\gamma$, IL- 2 y FNT- $\alpha$ que de alguna manera limitan la proliferación de $M$. leprae, restringiendo a pocas lesiones cutáneas asimétricas, con placas eritematosas, de borde externo elevado, centro hipocrómico y con alteración de la sensibilidad local como hipoestesia o anestesia. Puede incluir infiltración y engrosamiento de nervios periféricos detectables al examen físico y suele tener escasos BAAR en las lesiones o incluso pueden estar ausentes (forma paucibacilar $)^{8-10}$. En el otro extremo, se encuentra la forma lepromatosa con lesiones múltiples y simétricas, de bordes indefinidos, de color café o eritematosas, no necesariamente con alteraciones de la sensibilidad. Estas pueden progresar a placas o nódulos (lepromas) que dan a la cara un aspecto leonino (facie leonina), y comprometer los párpados o cejas con pérdida de cilios (madarosis ciliar o supraciliar). En la forma lepromatosa predominan los linfocitos CD8 y hay síntesis de IL-4, IL-5 e IL-10 que limitan la actividad de los macrófagos y favorecen la proliferación de $M$. leprae con lesiones multibacilares y detección de BAAR. La formación de anticuerpos no tiene un rol protector ${ }^{8,9}$. Nuestro paciente claramente sufrió una forma borderline lepromatosa, según el número de lesiones y el hallazgo de BAAR en las muestras de tejidos. Mycobacterium leprae puede comprometer los nervios periféricos y causar neuritis con dolor o alteraciones de sensibilidad. La neuropatía periférica de la EH es mixta con compromiso sensorial, motor y autonómico, ya sea con un perfil mononeurítico o de neuritis múltiple. Esto se traduce en hipoestesia/anestesia, paresia o parálisis, atrofia muscular, deformaciones en las articulaciones por desbalance motor, alteraciones vasomotoras (isquemia/ necrosis) y en las glándulas sudoríparas y sebáceas. Estas alteraciones contribuyen al desarrollo de lesiones en las extremidades o córnea, con úlceras, heridas profundas, infección secundaria, reabsorción ósea y deformidades, contribuyendo a la discapacidad y estigma social. En la mucosa nasal permiten cambios atróficos, perforación septal y colapso del tabique nasal ${ }^{8,9,11}$.

La transmisión de $M$. leprae ocurre a través de gotitas respiratorias pero la $\mathrm{EH}$ es poco frecuente en los contagiados. Cerca de $0,5 \%$ de los contactos de la forma paucibacilar y un 3\% de la forma multibacilar desarrollará lepra en los años siguientes (rango: seis meses-20 años; promedio dos a cuatro años) ${ }^{12}$. El riesgo de desarrollar la enfermedad depende no solo de la forma bacilar del caso

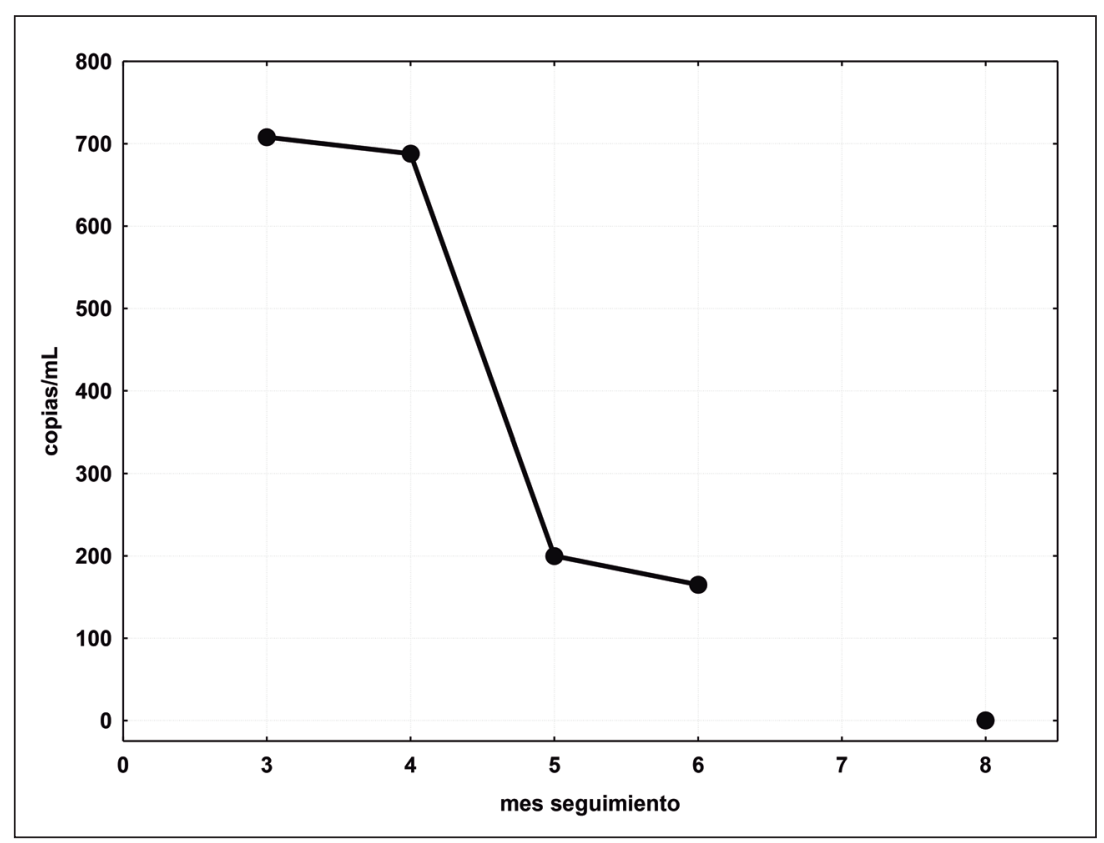

Figura 6. Amplificación de Mycobacterium leprae por RPC en tiempo real desde muestras nasofaríngeas según mes de tratamiento. Al $8^{\circ}$ mes de tratamiento no hubo detección. No se tomó muestra al $7^{\circ}$ mes.

índice ya comentada, sino que también de la cercanía con él, ya que el riesgo aumenta en los contactos domiciliarios y la consanguineidad con el paciente índice, debido a una susceptibilidad genética para desarrollar $\mathrm{EH}^{9,12,13}$. Los largos períodos de incubación obligan a examinar anualmente a los contactos por al menos 10 años. Estudios con técnicas moleculares han permitido identificar la presencia de $M$. leprae en secreciones o en la mucosa nasal en una proporción elevada de los pacientes con EH, especialmente con la forma multibacilar (75\%), aunque con cifras no despreciables para la forma paucibacilar $(45 \%)^{14}$. Estos antecedentes más la presencia de una forma multibacilar, son compatibles con la lenta desaparición de secuencias genéticas de $M$. leprae de la mucosa nasal en nuestro paciente (presencia al menos hasta el sexto mes). La positividad de $M$. leprae en la mucosa nasal entre los contactos domiciliarios es elevada (39-50\%), pero su presencia no está asociada al riesgo de desarrollar la enfermedad activa. Los factores ligados a este riesgo incluyen la presencia de $\mathrm{ADN}$ de $M$. leprae en muestras de sangre en los contactos o una prueba serológica con anticuerpos positivos para el antígeno fenólico glicolípido 1 de $M$. leprae (PGL-I) ${ }^{14}$. El riesgo de EH disminuye con la vacuna BCG (odds ratio 0,44 ) debido a la cercanía filogenética entre $M$. leprae y $M$. bovis. Este factor protector es utilizado en Brasil, administrando una nueva dosis de vacuna BCG como estrategia preventiva entre los contactos de cada caso ${ }^{15,16}$. También ha sido incorporada en Chile para el manejo de los contactos ${ }^{17}$. El reservorio 
de la EH es casi exclusivamente humano, existiendo unos pocos casos zoonóticos ligado al contacto con armadillos en ciertas zonas geográficas ${ }^{18}$.

El diagnóstico de EH se establece por un cuadro clínico compatible y la presencia de BAAR en muestras de tejido. Sin embargo, la presencia de $M$. leprae puede estar ausente en algunas formas paucibacilares, por lo que el diagnóstico se hace más inespecífico en estas circunstancias. Las pruebas serológicas, la histología y las técnicas moleculares permiten auxiliar el diagnóstico en casos dudosos. Lamentablemente, en regiones endémicas, el anticuerpo anti PGL-I (phenolic glicolipid I) es detectado en cerca de $50 \%$ de los pacientes con $\mathrm{EH}$, indicando una sensibilidad limitada especialmente en las formas paucibacilares. Su especificidad también está comprometida, ya que está presente en $10 \%$ de pacientes con tuberculosis ${ }^{19}$. La histología es variable, pudiendo o no demostrar granulomas no caseosos o BAAR. Un hallazgo sugerente es el compromiso de los filetes nerviosos, especialmente si se asocian a presencia de BAAR ${ }^{15}$. A diferencia de otras micobacterias, $M$. leprae no es cultivable en medios artificiales, por lo que la presencia de BAAR en tejidos, sin desarrollo posterior en medios de cultivo como ocurrió en nuestro caso, agrega otro elemento de confirmación al diagnóstico.

Las herramientas genéticas como la RPC y la secuenciación genética, posibles después de la completa caracterización del genoma de $M$. leprae el 201120, han revolucionado el conocimiento sobre la $\mathrm{EH}$, permitiendo en algunos pacientes la confirmación en caso de duda diagnóstica, el conocimiento sobre sus mecanismos de transmisión, rol del reservorio humano y zoonótico, respuesta a la terapia y la identificación de mecanismos de resistencia al tratamiento ${ }^{21-27}$. Más aún, estas tecnologías han sido aplicadas tanto en muestras frescas como en muestras fijadas en parafina. El papel de la RPC es especialmente relevante en los casos de duda diagnóstica, como pueden ser los paucibacilares y también con compromiso neurológico aislado, sin lesiones cutáneas. También podría ser útil en una serie de cuadros cutáneos con lesiones hipocrómicas o granulomatosas de difícil diagnóstico diferencial, tales como leishmaniaisis, pitiriasis alba, sarcoidosis, tuberculosis cutánea u otras patologías. Varios blancos genéticos han sido aplicados en identificación tales como el antígeno rico en prolina (pra), elementos repetitivos de M. leprae (RLEP), superóxido dismutasa (sod), ARN ribosomal $16 \mathrm{~S}$, proteína de estrés térmico 65 ( $h s p 65)$, RNA polimerasa ( $r p o B)$, etc. En algunos casos, la identificación se ha efectuado mediante la simple detección de los amplicones deseados y en otras con secuenciación y comparación con bases de datos genéticas. En nuestro paciente se utilizó una muestra combinada de amplificación seguida de secuenciación para dos blancos genéticos, con resultado posi- tivo. Además, éstas técnicas se utilizaron para conocer la duración de la portación nasofaríngea del agente que en este caso se prolongó aproximadamente seis meses. Aunque se ha descrito portación de más de un año a pesar del tratamiento y que se prefiere el seguimiento clínico en lugares en que el estudio molecular no está disponible, nuestra opinión es que la RPC podría ser utilizada para confirmar la adherencia al tratamiento, el que no es supervisado como la tuberculosis. De acuerdo a nuestra información, este sería el primer caso publicado con estudio molecular en Chile.

La EH es una enfermedad tratable y curable gracias a la disponibilidad de compuestos eficaces y seguros. La dapsona (una sulfona) fue introducida el año 1946 como monoterapia requiriendo varios años de tratamiento y asociándose al desarrollo de resistencia en algunos casos. El año 1982, la OMS adoptó el esquema combinado que se ha convertido en el estándar y se distribuye gratuitamente (en Chile a través del Programa de Control de la Tuberculosis). El uso combinado impide el desarrollo de cepas resistentes, especialmente ante la alta carga bacilar en la forma multibacilar $\left(10^{9} / \mathrm{g}\right.$ de epidermis; $10^{11}$ por paciente $)$ y permite el control de $M$. leprae en plazos relativamente cortos (6 a 12 meses para la forma paucibacilar y multibacilar, respectivamente) ${ }^{11,15,28}$.

La OMS recomienda clasificar a los pacientes en dos grupos: la forma paucibacilar ( $\leq$ cinco lesiones) y multibacilar ( $>$ cinco lesiones o presencia de BAAR) y aplicar el tratamiento según esta clasificación: $600 \mathrm{mg}$ de rifampicina mensual más dosis diarias de $100 \mathrm{mg}$ de dapsona por 6 meses para la forma paucibacilar y pulsos mensuales de $600 \mathrm{mg}$ de rifampicina con $300 \mathrm{mg}$ de clofazimina seguido de dosis diaria de $100 \mathrm{mg}$ de dapsona y $50 \mathrm{mg}$ de clofazimina por 12 meses para la forma multibacilar. Las tasas de recaídas con estos esquemas son muy bajas $(<1 \%)$ y los esquemas bien tolerados ${ }^{28}$. Las primeras lesiones en responder son las mucosas y luego las cutáneas. La regresión de los lepromas y del engrosamiento de la piel es más lenta. Las lesiones tróficas, infiltración de nervios y problemas sensorio-neurales son más refractarias. El tratamiento precoz es fundamental para evitar lesiones permanentes y discapacidades ${ }^{29}$.

Pueden observarse variados efectos adversos durante el tratamiento. En el caso de rifampicina, molestias gastrointestinales, colestasia, artralgias, hepatitis, molestias tipo influenza, pigmentación de la orina e inducción citocromal. Clofazimina genera un cambio de color en la piel con pigmentación café o rojiza, además de molestias gastrointestinales ${ }^{28}$. Dapsona puede producir casos raros de metahemoglobinemia y en forma dosis dependiente una anemia hemolítica no autoinmne que no tiene significación clínica en la mayor parte de las personas pero que es más intensa y puede ser sintomática en personas con déficit de $\mathrm{G6PD}^{30}$. Consideramos importante descartar este déficit 
por la ascendencia de nuestro paciente. En ausencia de esta anormalidad, el impacto en la caída de la hemoglobina fue mínimo. Además de observar la respuesta de las lesiones al tratamiento y las reacciones adversas a medicamentos, durante el seguimiento deben observarse los denominados estados reaccionales que resultan del desbalance inmune entre $M$. leprae y el hospedero. Consisten en cuadros inflamatorios sistémicos que se clasifican en dos tipos: reacción reversa tipo 1 , propias de pacientes borderline (entre pauci y multibacilar) y la reacción tipo 2, asociada a la forma multibacilar. En las de tipo 1 hay exacerbación de las lesiones cutáneas y neurológicas, desarrollo de úlceras o edema de pies y manos. Los casos más intensos pueden ser tratados con corticoesteroides. En las de tipo 2, aparecen lesiones tipo eritema nodoso. En ocasiones aparece fiebre, cefalea o iridociclitis. Pueden requerir un tratamiento con corticoesteroides o talidomida.

La EH es una enfermedad mítica para la población general, asociada a contagiosidad, deformaciones y segregación forzada. Genera un alto nivel de estigma y comentarios sociales, incluyendo vertientes xenofóbicas ante casos en inmigrantes. Actualmente, la $\mathrm{EH}$ es una enfermedad de baja contagiosidad, tratable y curable que no requiere una segregación y los pacientes pueden continuar con su vida en forma normal. Ello no implica que la vida sea fácil para estos pacientes ya que la sensación de abandono y rechazo es prevalente y observada en países desarrollados y subdesarrollados ${ }^{31}$. El equipo médico debe proteger la confidencialidad de los datos y apoyar psicológicamente al paciente.

Como en nuestro paciente, la $\mathrm{EH}$ en inmigrantes se caracteriza por un largo período sintomático antes del diagnóstico y que supera los años, intervalo que no es muy diferente al retraso diagnóstico en países con muy baja endemia. Además, cerca de un tercio recibe diagnósticos alternativos antes del reconocimiento final de $\mathrm{EH}^{32}$. Es muy probable que este escenario se reproduzca en Chile por la inexperiencia clínica.

La prevención de la $\mathrm{EH}$ se ha logrado mediante la mejoría de las condiciones de vida de la población, con su impacto en un menor hacinamiento domiciliario, en el tratamiento de los casos y su gratuidad, en la pesquisa y seguimiento de los contactos y en medidas auxiliares como terapia o vacuna $\mathrm{BCG}$ entre los $\operatorname{contactos}^{16}$. Al respecto, una dosis de vacuna $\mathrm{BCG}$ tiene una eficacia de un 55\% para reducir el riesgo de $\mathrm{EH}$ y una segunda dosis demuestra un efecto aditivo discreto $(59 \%)^{16}$. En Brasil por ejemplo, se aplica una dosis de BCG a cada contacto identificado ${ }^{13}$. Rifampicina en dos pulsos separados por cuatro meses tiene una eficacia aproximada de 40-70\% para reducir el riesgo de enfermedad entre los contactos ${ }^{16}$.

Agradecimientos: Los autores desean expresar el valioso aporte de Juan Carlos Hormazabal, Jefe del Subdepto. de Enfermedades Infecciosas del Departamento de Laboratorio Biomédico y Jorge Fernández, del Subdepartamento de Genética Molecular, ambos del Instituto de Salud Pública de Chile, por su valioso aporte en el estudio del caso.

\section{Resumen}

La enfermedad de Hansen (EH) es una infección secundaria a Mycobacterium leprae, de curso crónico y que afecta preferentemente la piel y los nervios periféricos. Es una condición emergente en Chile debido a la migración humana. Presentamos un caso que afectó a un trabajador inmigrante desde Haití, que presentó antes de su arribo múltiples lesiones cutáneas en placas, con hipoestesia y madarosis unilateral. El diagnóstico de la forma multibacilar se estableció por los hallazgos clínicos, la presencia de bacilos ácido-alcohol resistentes en una muestra cutánea y la detección de células inflamatorias alrededor de los terminales nerviosos y granulomas en una biopsia de piel, desde donde se amplificaron segmentos específicos de los genes rpoB y $h s p 65$ de $M$. leprae. El paciente fue tratado con el esquema combinado estándar de la OMS para la forma multibacilar durante un año, con regresión parcial de las lesiones. Durante el seguimiento se detectó por RPC una disminución del número de copias del gen rpoB de $M$. leprae en muestras nasofaríngeas hasta el sexto mes. El registro de enfermedades de notificación obligatoria demuestra un incremento reciente de casos de $\mathrm{EH}$ en Chile, todos relacionados con población migrante. La enfermedad de Hansen es una nueva condición clínica y los clínicos deben estar atentos a esta posibilidad diagnóstica. Las pruebas moleculares pueden ayudar en el diagnóstico y seguimiento.

\section{Referencias bibliográficas}

1.- WHO. Global leprosy update, 2015: time for action, accountability and inclusion. Wkly Epidemiol Rec 2016; 91: 405-20.

2.- Rojas N, Silva C. Informe Obimid. La migración en Chile. Breve reporte y caracterización. 2016. Disponible en: http:// www.extranjeria.gob.cl/media/2016/08/ informe_julio_agosto_2016.pdf (Fecha de acceso: septiembre de 2017).

3.- Payá E. Rapa Nui y la lepra. Rev Chilena Infectol 2009; 26: 54. doi: /S071610182009000100008 .

4.- Díaz R. Infección por Mycobacterium leprae en un habitante de la Isla de Pascua, Chile 1993.
Rev Chil Tecnol Méd 1996; 17: 797-9.

5.- Concha M, Cossio L, Salazar I, Fich F, Pérez C, González S. Enfermedad de Hansen: Revisión a propósito de un caso. Rev Chilena Infectol 2008; 25: 64-9. doi: /S071610182008000100013.

6.- Telenti A, Marchesi F, Balz M, Bally F, Böttger E C, Bodmer T J. Rapid identification 
of mycobacteria to the species level by polymerase chain reaction and restriction enzyme analysis. J Clin Microbiol 1993; 31: 175-8.

7.- $\quad$ Sekiguchi J, Miyoshi-Akiyama T, Augustynowicz-Kopeć E, Zwolska Z, Kirikae F, Toyota E, et al. Detection of multidrug resistance in Mycobacterium tuberculosis. J Clin Microbiol 2007; 45: 179-92.

8.- Jacobson R R, Krahenbuhl J L. Leprosy. Lancet 1999; 353: 655-60.

9.- Lastória J C, Abreu M A. Leprosy: review of the epidemiological, clinical, and etiopathogenic aspects - Part 1. An Bras Dermatol 2014; 89: 205-18.

10.- Marcos L A, Conerly S, Walker S. Leprosy. Am J Trop Med Hyg 2014; 91: 216. doi: 10.4269/ ajtmh.13-0668.

11.- Walker S L, Lockwood D N. Leprosy. Clin Dermatol 2007; 25: 165-72.

12.- Sales A M, Ponce de León A, Düppre N C, Hacker M A, Nery J A, Sarno E N, et al. Leprosy among patient contacts: a multilevel study of risk factors. PLoS Negl Trop Dis 2011; 5: e1013. oi: 10.1371/journal. pntd.0001013.

13.- Sauer M, Salomão H, Ramos G B, D'Espindula H R, Rodrigues R S, Macedo WC, et al. Genetics of leprosy: expected and unexpected development and perspectives. Clin Dermatol 2015; 33: 99-107. doi: 10.1016/j. clindermatol.2014.10.001.

14.- Araujo S, Freitas L O, Goulart L R, Goulart I M. Molecular evidence for the aerial route of infection of Mycobacterium leprae and the role of asymptomatic carriers in the persistence of leprosy. Clin Infect Dis 2016; 63: 1412-20.

15.- Lastória J C, Abreu M A. Leprosy: a review of laboratory and therapeutics aspects-Part 2. An Bras Dermatol 2014; 89: 389-401.

16.- Richardus J H, Oskam L. Protecting people against leprosy: chemoprophylaxis and immunoprophylaxis. Clin Dermatol 2015; 33:19-25. doi: 10.1016/j. clindermatol.2014.07.009.

17.- MINSAL, Chile. Manual de organización y procedimientos para la lepra (Enfermedad de Hansen). Disponible en: https://diprece. minsal.cl/wrdprss_minsal/wp-content/ uploads/2017/12/2017.12.21_MANUAL-DELEPRA.pdf (Fecha de acceso: 25 de agosto de 2018).

18.- Truman R W, Singh P, Sharma R, Busso P, Rougemont J, Paniz-Mondolfi A, et al. Probable zoonotic leprosy in the southern United States. N Engl J Med 2011; 364:1626-33. doi: 10.1056/ NEJMoa1010536.

19.- Silva R C, Lyon S, Araos R, Lyon A C, Grossi M A, Lyon S H, et al. The result patterns of ML Flow and ELISA (PGL-I) serological tests in leprosy-endemic and non-endemic areas. Rev Soc Bras Med Trop 2008; 41 Suppl 2: 19-22.

20.- Cole S T, Eiglmeier K, Parkhill J, James K D, Thomson N R, Wheeler P R, et al. Massive gene decay in the leprosy bacillus. Nature 2001; 409: 1007-11.

21.- Tiwari V, Malhotra K, Khan K, Maurya P K, Singh A K, Thacker A K, et al. Evaluation of polymerase chain reaction in nerve biopsy specimens of patients with Hansen's disease. J Neurol Sci 2017; 380: 187-90. doi: 10.1016/j. jns.2017.07.038.

22.- Martínez A N, Talhari C, Moraes M O, Talhari S. PCR-based techniques for leprosy diagnosis: from the laboratory to the clinic. PLoS Negl Trop Dis 2014; 8: e2655. doi: 10.1371/journal. pntd.0002655.

23.- Romero-Montoya M, Beltrán-Alzate J C, Cardona-Castro N. Evaluation and monitoring of Mycobacterium leprae transmission in household contacts of patients with Hansen's disease in Colombia. PLos Negl Trop Dis 2017; 11: e0005325. doi: 10.1371/journal. pntd.0005325.

24.- Araujo S, Goulart L R, Truman R W, Goulart I $\mathrm{M} \mathrm{B}$, Vissa V, Li W, et al. qPCR-high resolution melt analysis for drug susceptibility testing of Mycobacterium leprae directly from clinical specimens of leprosy patients. PLos Negl Trop Dis 2017; 11: e0005506. doi: 10.1371/journal. pntd.0005506.
25.- Yan W, Xing Y, Yuan L C, De Yang R, Tan F Y, Zhang Y, et al. Application of RLEP realtime PCR for detection of $M$. leprae DNA in paraffin-embedded skin biopsy specimens for diagnosis of paucibacillary leprosy. Am J Trop Med Hyg 2014; 90: 524-9. doi: 10.4269/ ajtmh.13-0659.

26.- Zhao Z, Liu X W, Jia J, Cai L, Zhang J Z. Rapid identification of Mycobacterium leprae by polymerase chain reaction-restriction fragment length polymorphism analysis of the heat shock protein 65 from skin specimens. Chin Med J (Engl) 2015; 128: 2964-6. doi: 10.4103/0366-6999.168076.

27.- Turankar R P, Pandey S, Lavania M, Singh I, Nigam A, Darlong J, et al. Comparative evaluation of PCR amplification of RLEP, 16S rRNA, rpoT, and SOD gene targets for detection of M. leprae DNA from clinical and environmental samples. Int $\mathrm{J}$ Mycobacteriol 2015; 4: 54-9. doi: 10.1016/j. ijmyco.2014.11.062.

28.- Kar H K, Gupta R. Treatment of leprosy. Clin Dermatol 2015; 33: 55-65. doi: 10.1016/j. clindermatol.2014.07.007.

29.- Brandsma J W, Van Brakel W H. WHO disability grading: operational definitions. Lepr Rev 2003; 74: 366-73.

30.- Gómez-Manzo S, Marcial-Quino J, VanoyeCarlo A, Serrano-Posada H, Ortega-Cuellar D, González-Valdez A, et al. Glucose-6-phosphate dehydrogenase: Update and analysis of new mutations around the world. Int J Mol Sci 2016; 17: e2069.

31.- Roosta N, Black D S, Rea T H. A comparison of stigma among patients with leprosy in rural Tanzania and urban United States: a role for public health in dermatology. Int J Dermatol 2013; 52: 432-40. doi: 10.1111/j.13654632.2011.05226.x.

32.- Norman F F, Fanciulli C, Pérez-Molina J A, Monge-Maillo B, Lópe-Vélez R. Imported and autochtonous leprosy presenting in Madrid (1989-2015): a case series and review of the literature. Travel Med Infect Dis 2016; 14: 33149. doi: 10.1016/j.tmaid.2016.06.008. 